\title{
Effects of Performance Ranking in Mathematics on Students' and Teachers' Identity Development
}

\author{
Samson Murithi Njiru', Milcah Njoki Nyaga ${ }^{2}$, Simon Karuku ${ }^{2}$ \\ ${ }^{1}$ Department of Mathematics, Kitui Teachers College, Kitui, Kenya \\ ${ }^{2}$ Department of Education, University of Embu, Embu, Kenya
}

Email address:

murithisamson@gmail.com (S. M. Njiru), nyaga.milcah@embuni.ac.ke (M. N. Nyaga), simon.karuku@embuni.ac.ke (S. Karuku)

\section{To cite this article:}

Samson Murithi Njiru, Milcah Njoki Nyaga, Simon Karuku. Effects of Performance Ranking in Mathematics on Students' and Teachers' Identity Development. International Journal of Secondary Education. Vol. 7, No. 1, 2019, pp. 17-28. doi: 10.11648/j.ijsedu.20190701.14

Received: February 4, 2019; Accepted: March 21, 2019; Published: April 29, 2019

\begin{abstract}
Student and teacher identities are generally considered to influence students' academic performance in Mathematics. The objective of the study reported in this paper was to investigate the effects of performance ranking in Mathematics on students' and teachers' identity development. The participants for the study were Mathematics teachers and students in secondary schools in Embu County in Kenya. A random sample of 1989 students and 101 teachers drawn from a population of 41925 students and 414 teachers participated in the study. The study adopted a mixed methods research design. Data were collected through one-on-one semi-structured interviews, focus group discussions and surveys. Chi-square test was used to test the hypothesis; performance ranking does not mediate Mathematics students' and teachers' identity development. The findings indicate that, performance ranking is a tool used by teachers and students in giving them feedback on their level of capabilities as Mathematics teachers and students. Secondly, performance ranking influence Mathematics teachers in furthering their studies in Mathematics-related courses, and students in aligning themselves to their preferred careers. Additionally, the study revealed that performance ranking is a motivation for students to work hard so as to have good relationships with their teachers as teachers are friendly to the students at the top of the rank. Similarly, the students identify themselves with peers of their abilities as far as Mathematics is concerned. The study recommends that the practice of performance ranking in Mathematics should continue and be used as a tool to identify the best Mathematics classes, students and teachers so as to act as a benchmark to encourage the rest to learn from.
\end{abstract}

Keywords: Performance, Mathematics, Ranking, Identity, Teaching, Learning

\section{Introduction}

Over the recent years, attention has been given to the study of Mathematics in secondary schools. Success in other subjects is tied to good mathematical skills. Most of Kenyan education stakeholders wish to know how students and schools have faired in Mathematics at the end of secondary course after the Kenya Certificate of Secondary Education examination results are announced. The stakeholders believe that for a good course in the university the student must score a good grade in Mathematics. Therefore, the data on performance ranking may help a student or a teacher to align to their future career. For example if the student is at the top of the rank in Mathematics, he/she might desire to take courses whose prerequisite subject is Mathematics. Similarly, a teacher whose students do well in Mathematics may be motivated to further his/her studies in Mathematics related courses.

Performance ranking of schools and students in high stake tests is a common phenomenon in many parts of the world. Performance ranking differs in terms of the procedures used. In Britain, performance ranking started in 1990 where ranking of schools in examination was based on students' raw scores. Later, a study done by Leckie [1] recommended performance ranking based on contextual value-addition (CVA) to students. In Portugal, the publication of secondary school rankings began in 2001 [2]. Portuguese school rankings are based on the raw data of the scores obtained by students in a given selection of subjects. In Chile, the government employs school averages of standardized tests as indicators of effectiveness. Ranking from standardized 
achievement tests assist the parents in choosing effective (or high valued-added schools) for their children to attend and allocation of rewards and assistance by the government [3]. A study by Troncoso, Pampaka and Olsen [4] recommended the use of a 4-level random coefficient model to analyze progress in Mathematics in Chilean schools. This model explicitly assesses the variation between pupils, classrooms, secondary schools and local authorities. These factors are highly significant and crucial to estimate more precise and informative school effects for accountability purposes.

In Netherlands, ranking is done using value-added indicators [5]. Value-added indicators were developed to make a fair comparison of the performance across educational institutions. In most of these value-added indicators performance of students on tests or examinations is used to estimate differences in performance between educational institutions, while controlling for differences in student intake at entry of a formal stage of schooling.

In Uganda performance ranking is currently based on value-added after a long period of using students' raw marks [6]. The change to value-added measure was aimed at revealing the true picture of students' outcome in examinations. Use of students' raw scores in performance ranking measures created a misleading impression of school success. The value-added measure is fair because it controls for the students' entry mark. This move creates an intelligent school accountability system in which actions taken by the stakeholders in education are based on quality data [6]. In addition, the value-added measures challenge schools and students to work hard in order to register an improvement.

In Tanzania, secondary schools and students are ranked using two methodologies. Firstly, performance ranking is done according to the average raw score of students and schools in standardized national examination conducted by the National Examination Council of Tanzania [7]. Secondly, performance ranking is based on the students' and schools' improvement in average examination score from the previous year. These rankings are made available online and included in popular media such as newspapers, television, and radio. The performance rankings are used by local education officials and the Ministry of Education to monitor schools' performance [7].

In Kenya, performance ranking dates back to 1940, where students and schools were ranked based on their mean score in high stakes tests [8]. The publication of mean performance statistics for the top schools in the respective categories and top students in the nation was meant to make it possible to compare performance amongst schools and students and, by extension, the level of hard work on the part of the teachers and school administrators. This form of ranking was strictly based on students' academic performance in national standardized examinations and failed to take into consideration the disparities in such aspects as school facilities and students' entry behavior.

In 1999, the report on Totally Integrated Quality Education and Training (TIQET) recommended the abolishing of ranking of students and schools in order to enhance equity and quality of education [9]. This particular recommendation, however, was not implemented and therefore, the performance ranking of schools and students continued until 2014, when the government of Kenya banned the practice. The ban was as a result of unethical practices by schools such as forced repetition of students, examination malpractices among others in order to improve their rank. In addition, the government argued that, the ranking of students based on the grade a student earns in any particular subject in the final examination did not give a definitive assessment of the academic learning process [10].

The decision by the government to ban performance ranking, immediately triggered a rather animated debate between proponents, on the one hand, and opponents of performance ranking, on the other. The proponents of performance ranking petitioned the government to reconsider its decision on the ban arguing that they had no clear way of determining success (or its lack) in the education system. As a result of pressure, the government resolved to lift the ban on performance ranking of schools and students in national examinations [11]. A guideline on how ranking should be done is stipulated in the Kenya National Examinations Council (Amendment) Act, 2016. The act stipulates that, the Cabinet Secretary shall, in every academic year, rank institutions of basic education that offer primary education or secondary education based on academic performance in national examinations; and performance in co-curricular activities (Kenya Gazette Supplement No. 151, Acts 30). The guidelines are yet to be implemented. This is because performance ranking in national examination is still going on but take into considerations of high stakes tests.

Teaching and learning is entangled with identity development. Indeed, teaching and learning involve acquisition of knowledge, skills and attitudes that bring about change in a student [12]. A student who enters secondary school with a high grade is more likely to have a positive academic self-construct compared to the one with a low grade. A positive academic self-construct is associated with high goal setting, academic engagement and academic achievement [13]. In contrast, Bornholt [14] found that high school student intentions to continue studying a certain subject especially Mathematics is based on their personal identity rather than actual academic performance.

Performance ranking in Mathematics influence identity development in both teachers and students. The students who appear at the top of the rank may identify themselves as capable Mathematics learners while those at the bottom of the rank may identify themselves as poor Mathematics learners. Therefore, student's identity has a major influence on their self-esteem, self-confidence, motivation and effort expended in Mathematics [15]. When Mathematics classrooms have no capacity to foster positive Mathematical identities among students there are bounds to be negative consequences for Mathematics teaching and learning [16]. This paper reports preliminary findings of an ongoing study whose overall objective is to determine the effects of performance ranking on Mathematics teaching and learning. 
Specifically, this paper describes the effects of performance ranking on Mathematics students' and teachers' identity development.

\section{Literature Review}

A number of studies have shown that performance ranking has some effects on students' and teachers' identity development [17]. Opponents of performance ranking contend that performance ranking data create incentives for schools to ignore the low-achieving students and discourage students from working hard in Mathematics. Those students develop an identity of poor Mathematics learners. For example, a study done by Bandiera, Larcinese and Rasul [18] revealed that students at the bottom of the rank get discouraged by the feedback and vice versa. In turn this affects the low-achieving students in that they conclude that they are not good in Mathematics which affects their identity development by seeing themselves as not capable Mathematics students.

The effects of performance ranking are not unique to students but affects teachers also. A study by Pope [19] on ranking of teachers in Los Angeles revealed that highly-rated teachers perform worse and vice versa. Pope's study was on teachers but the factors affecting teachers after ranking could be similar to those affecting students. Moreover, if performance is a function of both ability and effort, where ability and effort are complements in performance, then the self-perceived ability will affect the optimal choice of effort [21]. Based on this explanation, top (bottom) performing students would choose higher (lower) effort, because this information encourages high ability (discourages low ability) students [21].

Ranking not only affect students and teachers but also has effects on health workers. For example providing information on rank, the top and most improved performance to Zambian health workers in a training program lowered test performance [20]. However, the effect was not statistically different from a treatment that just provided information on rank, suggesting that the additional information on top performers may not have had an independent effect. By contrast, possible public recognition for leaders in the form of a letter of congratulations or being featured in a newsletter improved performance, consequently, identifying themselves as good health workers in discharging their duties to the citizens because of the public recognition of their good work.

The proponents of performance ranking argue that rating of teachers could improve their performance. For example Bergman and Hill [17] found that publication of the outcome of the rating could give incentive on performance improvement through reputational and self-image concerns, as well as the ability to learn about one's effectiveness and learn from others' effectiveness. However, publishing performance information can also have negative effects by annoying and embarrassing employees. Similar effects can be realized in publication of students ranking in examinations. For example, parents and schools can respond in a way that reallocates students to teachers such that achievement gaps between high and low-performing students widen through identity formation [17].

Further, performance ranking of students improves students' performance which would in turn affect their identity development. For example a study by Azmat and Iriberri [21] examined the effect of relative performance feedback on student's future absolute performance. The study exploited a natural experiment that took place in a high school, where form one students received information about the average class score in addition to their own performance. Like Bandiera, Larcinese and Rasul [18] the findings were, that provision of relative performance feedback improves the performance of all students in the subsequent test. However, their effects were stronger at the tails of the ability distribution.

The effect of performance ranking of students on their identity development depends on gender. Murphy and Weinhardt [22] examined the effect of knowing one's rank position in examination results on future examination performance. The study revealed large and robust effects of being highly ranked in one class on the next class achievement. In addition, the study revealed that boys were more affected by knowing their rank than girls. The highly ranked boys performed better than the low ranked ones. According to Cherry and Ellis [23], rank-order grading provides incentives that yield greater student effort and therefore leads to better student performance. Cherry and Ellis [23], suggest that rank-order grading may generate significantly better student performance. While the improved outcomes arise mostly among high performers, it is not at the expense of low performers.

As illustrated in Figure 1, this paper conceptualizes performance ranking as an important determinant of student and teacher identity development.

This study conceptualized that performance ranking of students in secondary schools affects Mathematics students' and teachers' identity development. This could happen as the student can see themselves as good or poor Mathematics learner as a result of the rank they get. On the other hand, teachers can identify themselves as good Mathematics teachers depending on their students' performance in Mathematics. This study also envisages that, there could be intervening variable such as teacher attitudes, student's determination and attitude towards Mathematics as a subject.

This study adopted Erik Erikson's theory of identity development. The theory stipulates that identity is a configuration gradually integrating constitutional givens, idiosyncratic libidinal needs, favored capacities, significant identifications, effective defenses, successful sublimations and consistent roles $[24$, p. 66]. The theory further stipulates that identity provides one with a sense of wellbeing, a sense of being at home in one's body, a sense of direction in one's life and a sense of mattering to those who count [25]. Examination and evaluation are synonymous with continued identity development. A highly ranked student in Mathematics may develop a sense of well being; a sense of 
being at home in one's self and a sense of direction in one's life as indicated by Erik Erickson's theory [26]. Similarly, a competent Mathematics teacher may develop an interest of furthering his/her study in Mathematics related disciplines.

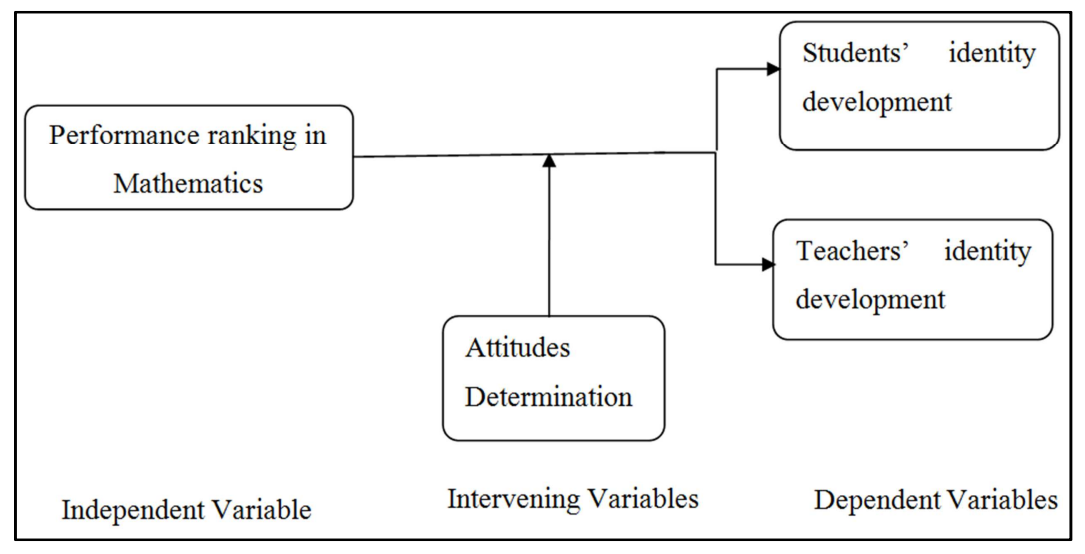

Figure 1. The Conceptual Framework of the Study.

In secondary schools, Mathematics students' and teachers' identity development is guided by knowledge management and knowledge sharing in Mathematics classrooms during teaching/learning. Therefore, ranking in Mathematics propels the highly ranked to continue creating and acquiring new skills which can guide towards identity development. Ranking in Mathematics provides teachers and students with an opportunity of understanding oneself and focus on one's future aspirations. This study adopted this theory since ranking schools and students in examination may help them in the identity formation. Once formed, this identity will provide the students with a sense of well being and a sense of direction in one's life as indicated by Erick Erickson's theory. Those ranked low may have serious problems in terms of competence and self-esteem.

\section{Objective and Hypothesis of the Study}

The objective of the study was to investigate the effects of performance ranking in Mathematics on teachers' and students' identity development. The hypothesis of the study was that performance ranking in Mathematics does not influence teachers' and students' identity development.

\section{Method and Materials}

In this study, mixed method design was used. Mixed method design is a procedure for collecting, analyzing and combining both quantitative and qualitative data in a single study [27]. The rationale for this approach is that quantitative method ensured breadth; that is, many Mathematics students and teachers were able to take part in the research providing a general picture of the research problem. The qualitative method enabled the researchers to have in-depth information by refining and explaining quantitative statistical results by exploring participants' views in more depth [28].

The study was carried out in Embu County in Kenya. Embu County lies between latitudes $0^{\circ} 8^{\prime}$ and $0^{\circ} 35^{\prime}$ South and longitudes $37^{\circ} 19^{\prime}$ and $37^{\circ} 42^{\prime}$ East. The target population was all the 194 secondary schools, 414 teachers of
Mathematics and 41,925 Mathematics students in secondary schools in Embu County.

The study used the multi-stage sampling technique. Secondary schools were grouped into five strata namely; private, national, extra-county, county and sub-county schools. Stratified sampling was employed to determine the sample size in each stratum. Random number generator was used to sample the particular secondary schools and Mathematics students which took part in the study in each category in all the classes. The sample size was 2090 respondents drawn from the different categories of secondary schools in Embu County.

Table 1. Research-participants sample size.

\begin{tabular}{llll}
\hline $\begin{array}{l}\text { Category of } \\
\text { school }\end{array}$ & $\begin{array}{l}\text { Student- } \\
\text { participants }\end{array}$ & $\begin{array}{l}\text { Teacher- } \\
\text { participants }\end{array}$ & Total \\
\hline Private & 130 & 8 & 138 \\
National & 92 & 7 & 99 \\
Extra County & 587 & 26 & 613 \\
County & 503 & 28 & 531 \\
Sub-County & 677 & 32 & 709 \\
TOTAL & 1989 & 101 & 2090 \\
\hline
\end{tabular}

The data were collected using interview schedules and questionnaires. The questionnaire contained nineteen Likerttype closed-ended questions. The participants scored the items using a five-point rating scale ranging from Strongly Agree to Strongly Disagree. In addition, an interview guide containing twenty open-ended questions and focus group discussion guide containing seventeen questions were used to collect data in the sampled secondary schools.

The study instruments were tested in secondary schools other than those in the study to determine their reliability. The respondents in the pilot study had similar characteristics with those in the actual study. The coefficient alpha method was used to obtain reliability of the instruments. The Cronbach Alpha formula was utilized [29] and [30]. The formula is illustrated in the equation 1 below.

$$
\alpha=\frac{\mathrm{n}}{\mathrm{n}-1}\left[1-\frac{\sum_{\mathrm{i}} \mathrm{V}_{\mathrm{t}}}{\mathrm{V}_{\mathrm{i}}}\right]
$$


In the formula above, $\alpha$ is the Cronbach alpha, $\mathrm{n}$ is the number of items, $\mathrm{V}_{\mathrm{i}}$ is the variance of the item scores and $\mathrm{V}_{\mathrm{t}}$ is the variance of the total scores. By definition, $\alpha$ is the average value of the reliability coefficients one would obtain for all possible combinations of items when split into two half-tests [31]. It is advantageous as a test of reliability technique since it requires the administration of only a single test to provide a unique estimate of the reliability for any given test. Cronbach coefficient alpha of reliability was computed by the help of SPSS. A coefficient alpha of 0.73 and 0.76 was obtained for Mathematics students and teachers research instruments respectively. The value obtained was high enough to be accepted as a reliable measure of consistency of the instruments.

\section{Results of the Study}

The study sought to establish how performance ranking mediates students' and teachers' identity development. Results of the findings are described in subsequent subheadings.

\subsection{Influence of Performance Ranking on Teachers' and Students'Self-esteem}

Self-esteem is the overall evaluation of a person's worth based on all the positive and negative self-perceptions that make one self-concept [32]. It is the summary judgment of everything a person can assess about himself/herself. The study sought to establish whether performance ranking promotes Mathematics teachers' and students' high self-esteem.

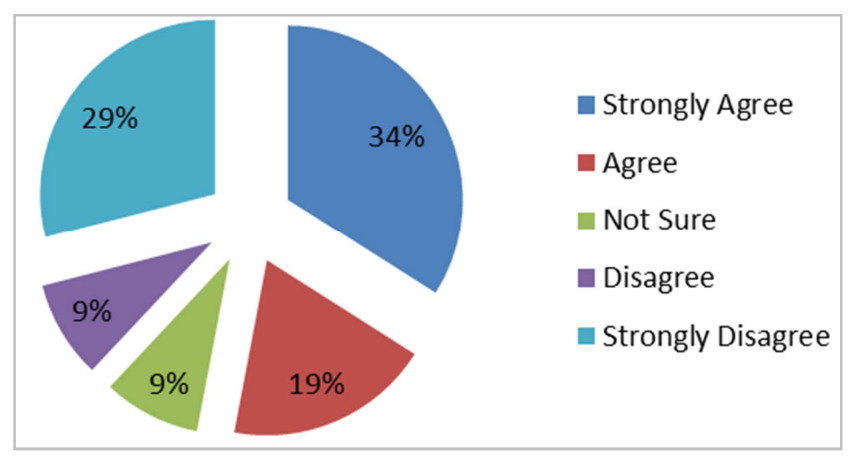

Figure 2. Teachers' opinion on whether performance ranking promotes students' and teachers' self-esteem.

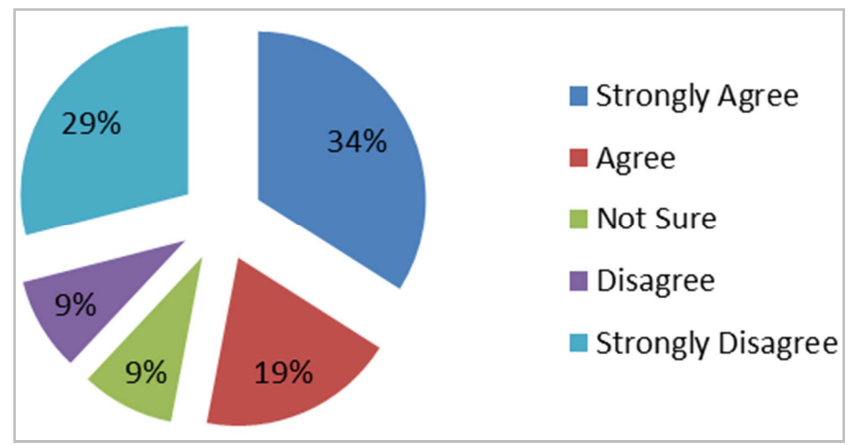

Figure 3. Students' opinion on whether performance ranking promotes students' self-esteem.
As shown in the Figures 2 and 3, survey findings revealed that about $70 \%$ of teachers and about $53 \%$ of students agreed that performance ranking promotes students' high selfesteem. Data from the interviews corroborated the above findings. A number of student-participants indicated that, their position in the performance ranking influenced how they perceived themselves as Mathematics learners.

I am good in Mathematics because I perform well in the subject. It is the only subject I get over $70 \%$. I realized I am good in Mathematics when I was in form 3 after I became serious with my studies. It feels good when I find myself at position one after any Mathematics examination. Everyone in the school knows that I am a very good student in Mathematics. I find myself being consulted many times by my fellow students (Form 3 student in a National school).

Hence, there is a strong relationship between secondary school students' self-esteem and performance ranking in Mathematics [33]. Bergman and Hill [17] observed that, rating of teachers could improve their performance as it acted as an incentive to performance improvement through reputational and self image concerns. This is an indication that highly ranked students are positive about performance ranking in Mathematics. Thereby helping the students to know their capability in Mathematics, and boost their selfesteem in the subject.

I can rate myself as a good student in Mathematics. This rating is because of the way I solve the Mathematics questions with ease. I realized I was good in Mathematics while in form 3 because of the way our Mathematics teacher used to make us aware of the many courses that are related to Mathematics. I realized I am good in Mathematics when I learned that I could assist other students to solve Mathematical problems. I am proud to be a good student in Mathematics (Form 4 student in a sub-county school).

It is important to note that performance ranking helps build the self-esteem of the learner, especially so if the learner is always at the top of the rank. The learner becomes confident to an extent that he/she feels like an expert in the subject (worth consulting). In Mathematics teaching and learning, students recognize the highly ranked and acknowledge them and regularly seek their assistance in the subject. Those at the top of the rank choose higher efforts in the subject. In addition, performance ranking influence teacher identity development. The teacher whose class is at the top of the rank is more confident than the rest. That is, just like the highly ranked students, the teacher's morale and esteem is boosted by ranking.

I am a good Mathematics teacher because, since I started teaching, my students have been passing in Mathematics. The Principal insists that I have to take lessons in all the examination classes. I feel good that the principal recognizes that I am a good Mathematics teacher (Form 3 teacher in a County school).

..... I am a good Mathematics teacher compared with my colleagues in the same department. This is because my class is always at the top of the other classes when examination analysis is done (Form 4 Teacher in a private school). 
This stresses the importance of performance ranking since the teacher cannot rank himself. Without performance ranking, the teacher will not know his/her level of performance. It therefore requires a neutral person to evaluate all the teachers' performance and rank them. This implies that performance ranking promotes students' and teachers' self-esteem.

\subsection{Influence of Performance Ranking on Teacher-Student Relationships}

Strong relationships between teachers and students are essential components to students' healthy academic development in Mathematics [34]. The study sought to establish whether performance ranking influences teacher-student relationships. Result from the survey data are presented in Figures 4 and 5.

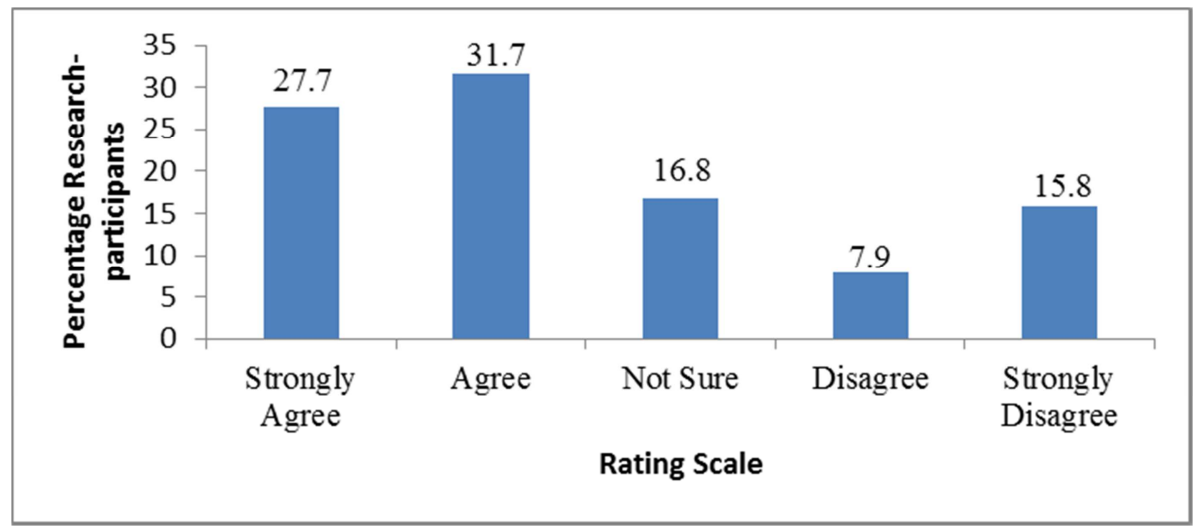

Figure 4. Teachers'opinion on whether performance ranking influences teacher-student relationships.

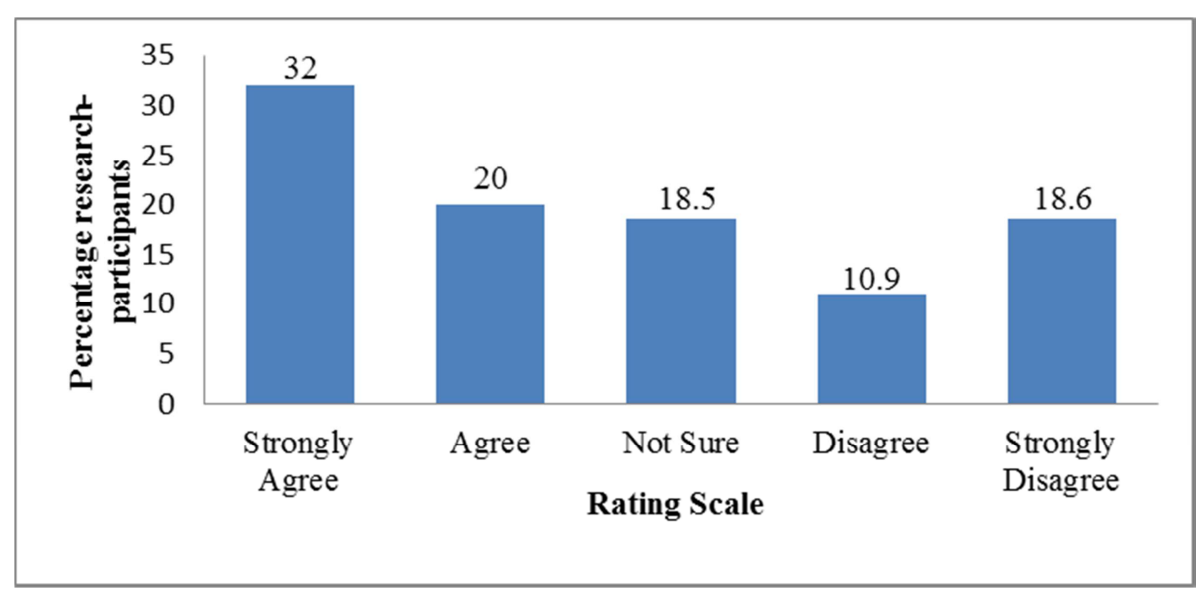

Figure 5. Students'opinion on whether performance ranking influences teacher-student relationships.

The survey study findings observed that, about $59 \%$ of teachers and about $52 \%$ of students were of the opinion that performance ranking indeed influences teacher-student relationships. Further interview with student-participants revealed that Mathematics teachers are friendly to students who are at the top of the rank in Mathematics. This move does not go well with the students at the bottom of the rank and they end up developing a sour relationship with the Mathematics teacher. They lose hope in Mathematics because they feel that the teacher has no room for them due to their low performance.

Top students in Mathematics are very friendly to our Mathematics teacher and the teachers are proud of them. Teacher sends them for small errands (Form 2 student in a County school).

.....performance ranking in Mathematics affects studentteacher relationship. This is because, those who are at the bottom of the rank fear being friendly to their Mathematics teacher because the teacher will keep complaining about their poor performance. The bright ones are also very reserved. They do not consult teacher (Form 1 student in a private school).

Students' good performance is a motivation to them to freely interact with teachers in and out of the Mathematics classrooms. Since students value good relationships with the teachers, they work hard to ensure their performance is in line with the demands of their teachers and guardians.

My performance in Mathematics enables me to have a good relationship with both parents and teachers. When I perform well the relationship is good but when my performance in Mathematics goes down my parents and teachers become uncomfortable with me. Since I like relating well with them I work hard to improve (Form 3 student in a sub-county school).

It is interesting to note that teachers are disconnected with the low ranked students to the extent of completely ignoring them during Mathematics teaching and learning. The students end up developing negative attitudes towards the teacher and eventually towards the subject. 
Our Mathematics teacher is fond of concentrating on bright students during the Mathematics lessons. During the lesson the teacher gives us an exercise and marks for the bright students only. Then the teacher introduces another topic. The low achievers are discouraged and hate the subject. The teacher has never marked my work since the start of the term and the term is five weeks to end (Form 1 student in an extra-county school).

Mathematics students at the top of the rank relate well with the Mathematics teachers while those at the bottom of the rank relate poorly because they feel shy to be near them for fear of being questioned about their low performance. Top performers in search of more understanding of the subject continually consult the teacher for more guidance on mathematical solving skills. As a result, a bond is created between them and the Mathematics teachers. In tandem with the study findings, Murray and Zvoch [35] observed that, as a result of assessment and ranking of students, teachers' relationship with students who have performed quite well is good. This implies that performance ranking influences teacher-student relationship. This is consistent with the views of the student-participants in that majority of students at the top of the rank relate well amongst themselves while teachers are friendly to the students at the top of the rank in Mathematics. Those at the bottom of the rank get de-motivated to study the subject which leads to low performance.

\subsection{Performance Ranking in Mathematics and Teacher Subject Mastery}

Since teaching involves imparting of knowledge and skills, it is therefore necessary for the teacher to understand subject matter before engaging students in class [36]. This is because a good mastery of the content enables the teacher to promptly deal with any misconception which arises during the lesson. The study aimed at establishing whether performance ranking helps teacher to know whether they are good Mathematics teachers or not.

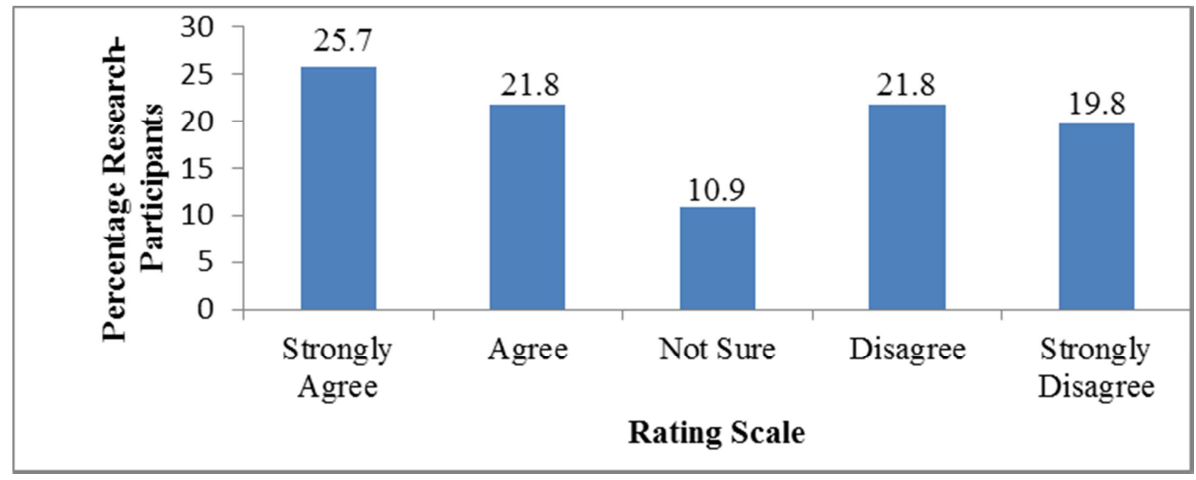

Figure 6. Teachers'opinion on whether performance ranking in Mathematics reflects their subject mastery.

As shown in the figure 6 , about $47 \%$ of teachers agreed that performance ranking reflects the teacher mastery of the Mathematics content. Students' achievement in Mathematics is a function of many factors. One of the major factors being subject mastery of the content by the teacher which determines selection of the appropriate teaching methods employed in Mathematics classrooms. Therefore, the class whose teacher has a good mastery of the subject matter in most cases obtain a high rank compared to the one taught by novice teachers. For the highly ranked teacher in Mathematics, there is a high level of confidence. It acts as an incentive and motivates the teacher intrinsically. It boosts the teacher's morale, the reason they feel good and proud of their teaching job.

I know I am a good Mathematics teacher because my students perform well in Mathematics. Sometimes student's performance is a function of many factors. For example the attitudes and effort towards the subject but the input of the teacher is key. The school is double streamed and the students in my class are always at the top of the rank (Teacher in an extra-county school).

To an extent teachers' effort in teaching is reflected by the students' performance in the subject. If the class is at the top of the rank comparatively then the class teacher is said to be a hard worker and has a thorough knowledge of the content.

....during the prize giving day I get the teacher of the year award. Those invited witness when I am being awarded. This is as a result of the effort I put towards my work (Teacher in an Extra-county school).

On the contrary, Pope [19] did a research on ranking of teachers in Los Angeles and found that highly-rated teachers perform their teaching duty worse and low-rated teachers perform better. Teaching duty performance may not automatically produce good Mathematics students but subject mastery is to some extent responsible for students' outstanding performance in Mathematics. Data from the survey and interviews indicated that the highly ranked students work hard to maintain their good performance.

My performance in Mathematics is not very good. I can rate myself as an average student in Mathematics since I am always near the bottom of the rank in Mathematics. The reason for rating myself as an average student is because I work hard but some topics in Mathematics are a problem to me (Form 1 student in a sub-county school).

Therefore, students' performance ranking in Mathematics is a key indicator to teachers whether they are capable Mathematics teachers or not. Similarly, students' performance is a key indicator to them whether they are good 
in Mathematics or not.

\subsection{Performance Ranking in Mathematics and Career Choice}

Career choice among students is a very significant phase in their lives. Therefore, it is important for the students to be careful in decision making taking into considerations all the guiding factors. Among the factors which influence students career choice is students' academic achievement in various subjects [37]. The study sought to ascertain whether performance ranking influence students in career choice. Results from the survey data are presented in Figures 7 and 8.

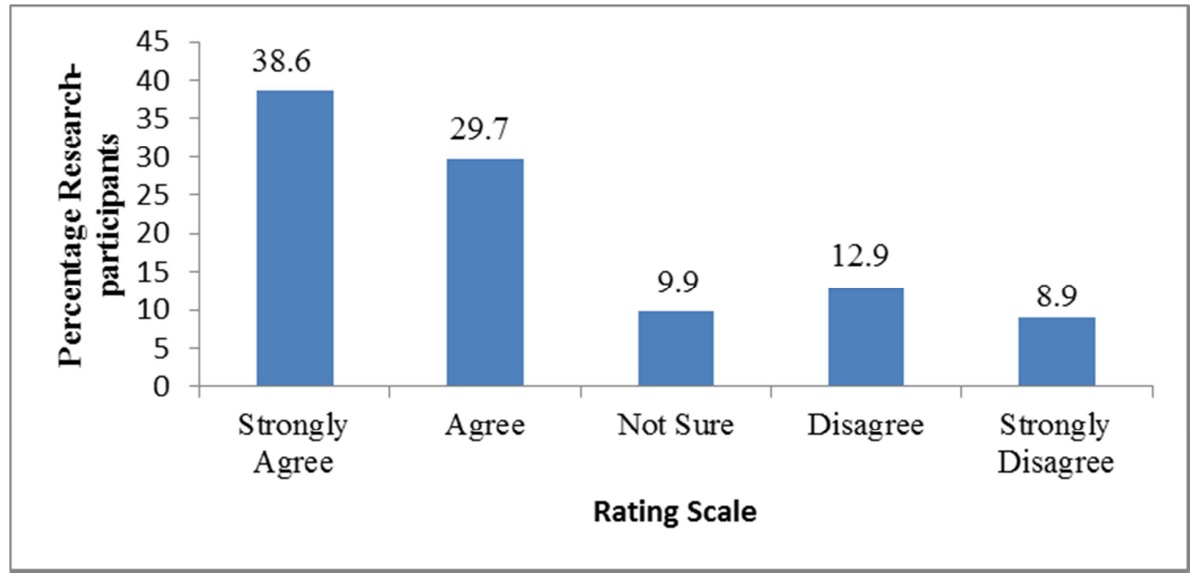

Figure 7. Teachers'opinion on whether performance ranking influences students in career choice.

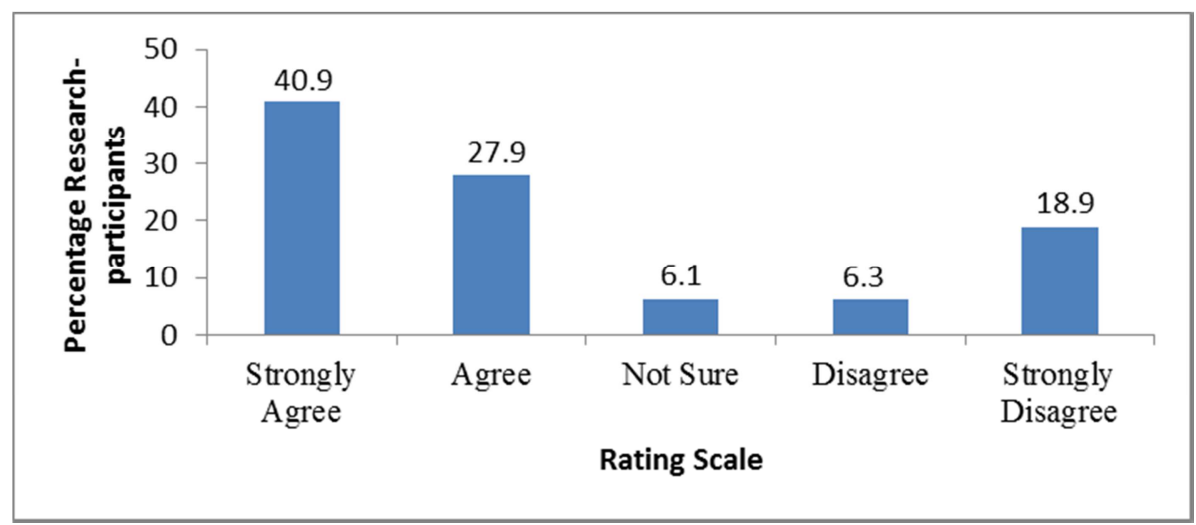

Figure 8. Students'opinion on whether performance ranking influences student career choice.

The survey results observed that about $68 \%$ of teachers and $68 \%$ of students were of the opinion that performance ranking guides students in choosing their career. In addition, interview with student-participants revealed that the students at the top of the rank choose career related to Mathematics while those at the bottom of the rank choose career not related to Mathematics irrespective of the marks obtained.

My career is to become an engineer. I aim at pursuing a career in electrical engineering. This is because I perform well in Mathematics and sciences (Form 4 student in a National school).

The same sentiments were echoed by teacher-participants.

Career choice is based on students' performance in various subjects. Therefore students who are good in Mathematics from experience choose career related to Mathematics. In my class I have 42 students and the ones at the top of rank in Mathematics have expressed interest in careers related to Mathematics. For example the top 5 are inclined to being engineers (Teacher in a National school).
This is a clear indication that performance ranking in Mathematics helps in orienting the secondary school students towards the courses to pursue after the secondary education. The students at the top of the rank are encouraged to further their studies in Mathematics related courses such as engineering, actuarial science and business courses.

I am a member of Guidance and Counseling Department. To guide students on areas to further their studies on we look at performance in the cluster subjects' requirements for the courses. Top performers in Mathematics are advised to further their studies in Mathematics related courses (Teacher in a County school).

In tandem with the study findings, Cherry and Ellis [23] noted that the importance of the grading system in motivating student learning arises from the significance of grades in signaling ability and learned knowledge. Students respond to grades at varying levels because grades are a key signal used by concerned parties.

Further, in line with the study findings Brown and Lent [16] assert that performance ranking help individuals 
understand how a variety of personal attributes (i.e., interests, values, preferences, motivations, aptitudes and skills) impact their potential success and satisfaction with different career options and work environments. Therefore, performance ranking plays a critical role in career choice among the secondary school students at the end of their course.

\subsection{Performance Ranking and Students' Involvement in Teaching/Learning Activities}

It was the interest of the study to establish whether performance ranking influences students' involvement in teaching and learning activities in Mathematics classrooms. Results from the survey are as shown in Figure 9.

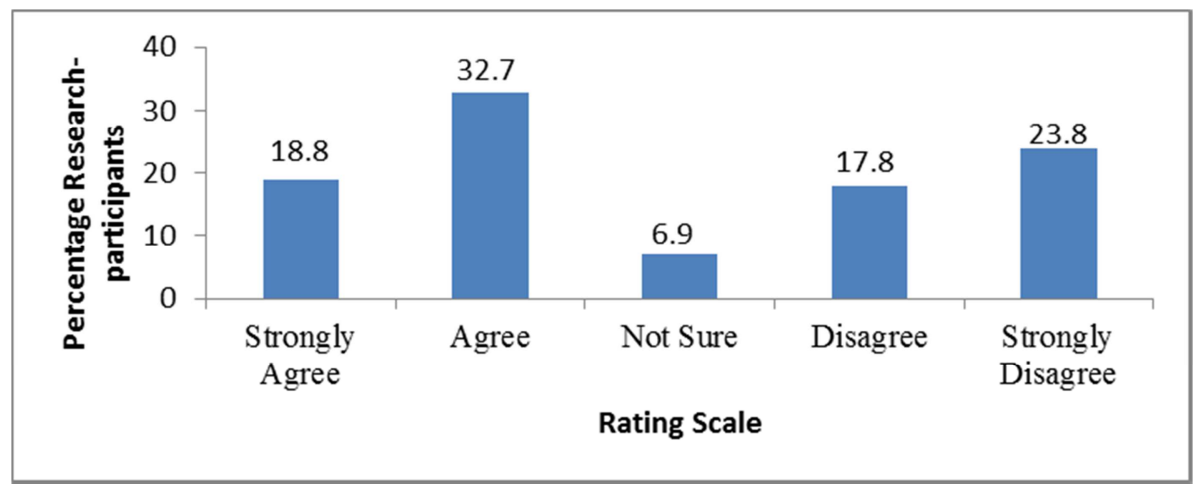

Figure 9. Performance ranking and students' involvement in teaching and learning activities.

As shown in figure 9 the survey data revealed that about $51 \%$ of teachers were of the opinion that performance ranking influence students' involvement in teaching/learning activities. Further, the results from the interviews revealed that Mathematics teachers ignore the students who are ranked at the bottom and concentrate with the ones at the top of the rank. This move does not go well with the below average students as they feel neglected. Their self-esteem is affected as they see themselves as poor Mathematics learners.

.... I feel bad because the teacher thinks that I know nothing in Mathematics. I feel not wanted during the lessons. I hate the subject. How I wish Mathematics was an elective subject because it would be the first subject to drop in form 3 during the subject selection (Form 2 student in a County school).

...those at the bottom of the rank, rarely participate actively during the Mathematics lessons. The average learners are friendly with me. They keep bothering me with questions (Teacher in a sub-county school).
The survey data, interviews and focus group discussions responses reveal that, the Mathematics teachers neglect the low achievers during Mathematics lessons. This implies that performance in Mathematics is a tool used by the Mathematics teachers consciously or subconsciously in Mathematics activities allocation during Mathematics teaching and learning. In turn Mathematics teaching and learning is negatively affected because the low achievers are discouraged and take a passive role throughout the lesson which translates to low performance in the subject.

\subsection{Performance Ranking in Mathematics and Subject Mastery}

The study sought to establish from students whether performance ranking makes them worry that they do not know enough Mathematics to do well in future Mathematics tests. Results from the survey are as shown in Figure 10.

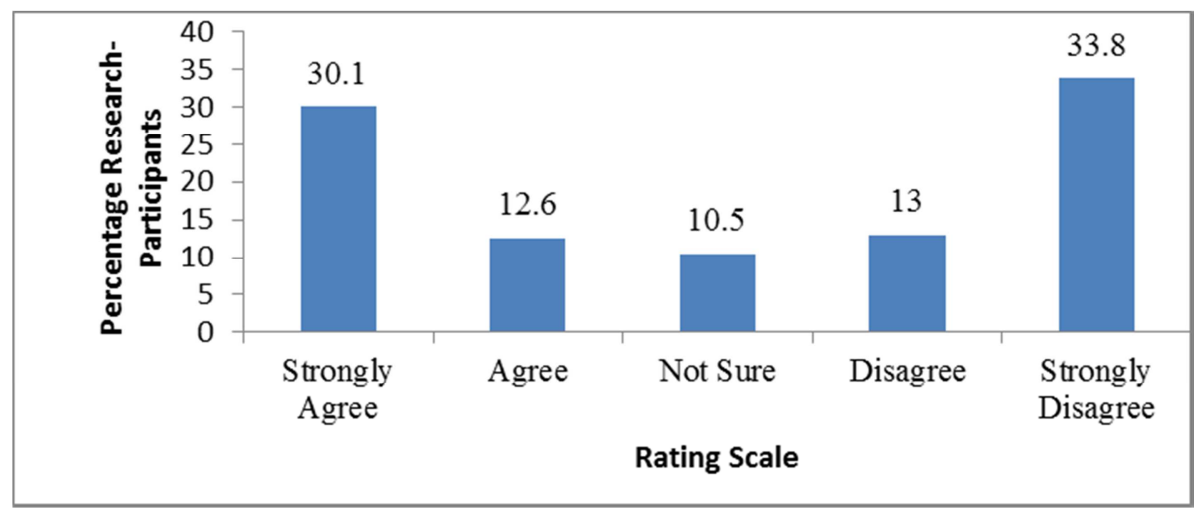

Figure 10. Students'opinion on whether performance ranking reflects comprehension of Mathematics.

The survey study findings observed that about $42 \%$ of students agreed that performance ranking makes them worry that they do not know enough Mathematics to do well in future Mathematics tests. Therefore, this is an indication that performance ranking does not make students worry that they do not know enough Mathematics to do well in future 


\section{Mathematics tests.}

Ranking affects students' performance in Mathematics negatively because they see as if they can't make it in the subject. On my side before I even sit for a Mathematics examination I know I will not get top position but that does not mean that I do not know Mathematics. Performance in Mathematics depends on variety of issues like students' preparedness, selection of questions by the teacher etc. Though presently I am performing poorly in Mathematics I have conviction that in future I will improve my performance (Form 2 student in a private school).

The study revealed that being at the top of the rank did not necessarily mean one is good in Mathematics. Sometimes the top rank depends on the entry behavior of students. In some cases a student is at the top of the rank but the score is very low. For example a student can be the best in Mathematics class with a score of $30 \%$. Therefore, a student might be at the top of the rank with a low grade which is below average. Further, the findings of this study revealed that performance ranking affected performance trends among the different categories of schools but did not significantly affect the trends of the individual students. These findings concur with those of Bradley, Crouchley, Millington and Taylor [38] who assert that, top ranked schools remained in the high performing category while the low ranked schools remained in the poor performing category thus widening the gap between the high and low achievers. Such findings are also similar to those of Lassabille et al. [39] that showed the gap between the best and worst schools had widened. The same argument is expressed by the office for standards in education [40] which found that performance trends indicated a widening gap between the performance of pupils in the highest and lowest ranked schools.

In regard to hypothesis (Ho): performance ranking does not mediate students' and teachers' identity development in Mathematics teaching and learning was tested using a Chisquare $\left(X^{2}\right)$ model at $95 \%$ confidence level. The results are as shown in Table 2.

Table 2. Chi-square test for the hypothesis- performance ranking does not mediate students' and teachers' identity development in Mathematics teaching and learning.

\begin{tabular}{lllllll}
\hline Independent variable & Hypothesis & chi test & Chi-sq. p value & Sig. Value & Result & Decision \\
\hline students' and teachers' identity development & $\mathrm{H}_{01}$ & 35.21 & 0.276 & 0.05 & $0.276>0.05$ & $\mathrm{H}_{01}:$ rejected \\
\hline
\end{tabular}

This means that the level of significance was 0.276 which is greater than 0.05 , the acceptable level of significance. Therefore, the null hypothesis (Ho): performance ranking does not mediate students' and teachers' identity development was rejected. This implies that performance ranking mediates students' and teachers' identity development.

\section{Conclusion}

The study found out that performance ranking mediates students' and teachers' identity development. First, students position in the performance ranking influence how they perceive themselves as Mathematics learners with those at the top of the rank labeling themselves as good Mathematics learners. Those at the bottom of the rank label themselves as poor Mathematics learners. Those at the top of the rank enjoy the benefit of good relationship with the teachers, an issue which does not go well with the low ranked students. Low ranked students end up losing hope in Mathematics because they feel that the teacher has no space for them due to their low performance.

Secondly, performance ranking provide a rating for the teachers to know their position as far as Mathematics subject mastery is concerned. For the highly ranked teacher, ranking in Mathematics gives the teacher more confidence. It acts as an incentive and motivates the teacher intrinsically. It boosts the teacher's morale, the reason they feel good and proud. This implies that performance ranking helps teacher to know whether they are good Mathematics teachers or not.

Further, performance ranking helps students in aligning themselves to their preferred career. Those at the top of the rank choose careers related to Mathematics while those at the bottom of the rank choose career not related to Mathematics irrespective of the marks obtained at the end of the secondary course. Additionally, performance ranking is a tool used by the department of Guidance and Counseling in advising students on the issues related to career choice.

Finally, it is important to note that performance ranking is not related to students' future performance in the subject. Therefore, it does not make students worry that they do not know enough Mathematics to do well in future Mathematics tests. Students' future performance is influenced by many factors such as the study habit developed and attitudes towards the subject among others.

\section{Recommendations}

Based on the findings, the study makes the following recommendations:

First, performance ranking should be encouraged in Mathematics teaching and learning as it motivates, boosts morale and helps both the Mathematics teachers and students build confidence and self-esteem.

Secondly, performance ranking should be used as a tool to identify the best Mathematics classes, students and teachers so as to act as a benchmark to encourage the rest to learn from, but not as a tool to intimidate the low performers. By so doing, no student will feel discouraged to learn Mathematics.

The study further recommends other studies on other subjects in relation to performance ranking to be conducted so as to ascertain the relevance of performance ranking in secondary schools in Kenya. 


\section{References}

[1] Leckie, G. England's multilevel model based value-added school league tables: Measuring and communicating statistical uncertainty to parents. Bulletin of the International Statistical Institute. 2013; 68: 824-829.

[2] Neves, T., Pereira, M. J., \& Nata, G. Head teachers' perceptions of secondary school rankings: Their nature, media coverage and impact on schools and the educational arena. Education as Change. 2014; 18(2):211-225.

[3] McEwan, P. J., Urquiola, M., Vegas, E., Fernandes, R., \& Gallego, F. A. School choice, stratification, and information on school performance: Lessons from Chile. Economia. 2008; 8(2): $1-42$.

[4] Troncoso, P., Pampaka, M., \& Olsen, W. Beyond traditional school value-added models: A multilevel analysis of complex school effects in Chile. School Effectiveness and School Improvement. 2015; 3(27): 293-314.

[5] Timmermans, A. C., Bosker, R. J., de Wolf, I. F., Doolaard, S. $\&$ van der Werf, M. P. C. Value added based on educational positions in Dutch secondary education. British Educational Research Journal. 2014; 40(6): 1057-1082.

[6] Crawfurd \& Elks. Improving the measurement of school quality with value-added Models: Lessons from high-income countries for developing countries (with an application in Uganda). Ark Education Partnerships Group, 2016.

[7] Blackmon, W. K. Using a value-added model to measure private school performance in Tanzania, Washington, D. C. Georgetown, 2017.

[8] Bogonko, S. N. Reflection on education in East Africa. Oxford University Press, Nairobi, 1992.

[9] Republic of Kenya. Totally integrated quality education and training (TIQET). Report of the Commission of Inquiry into the Education System of Kenya. Government Printer, Nairobi, 1999.

[10] Kithuure, J. Educators divided on school exams ranking ban. The Daily Nation Nairobi, Kenya, 2015, July 1.

[11] Republic of Kenya. National Assembly bills, 2016. Kenya Gazette Supplement, 2016.

[12] Wenger, E. Communities of practice: Learning, meaning, and identity. Cambridge University Press, Cambridge, UK, 1998.

[13] Bliuc, A. M., Ellis, R. A., Goodyear, P., \& Hendres D. M. The role of social identification as university student in learning: relationships between students' social identity, approaches to learning, and academic achievement. Educational Psychology; An International Journal of Experimental Educational Psychology. 2011; 31(5): 559-574.

[14] Bornholt, L. J. Self-concepts, usefulness and behavioural intentions in the social context of schooling. Educational Psychology. 2001; 21(1): 67-78.

[15] Swenson, R. R., \& Prelow, H. M. Ethnic identity, self-esteem, and perceived efficacy as mediators of the relation of supportive parenting to psychosocial outcomes among urban adolescents. Journal of Adolescence. 2005; 28(4): 465-477.

[16] Brown, S. D., \& Lent, R. W. (Eds.). Handbook of counseling psychology (4 $4^{\text {th }}$ ed), John Wiley, Hoboken, N. J, 2008.

[17] Bergman, P., \& Hill, M. The effects of making performance information public: Evidence from Los Angeles teachers and a regression discontinuity design SSRN. Retrieved August 3, 2016, from

http://papers.ssrn.com/sol3/papers.cfm?abstract_id=2615769, 2015

[18] Bandiera, O., Larcinese, V., \& Rasul, I. Blissful ignorance? A natural experiment on the effect of feedback on students' performance. Labour Economics. 2015; 34(1): 13-25.

[19] Pope, N. The Effect of teacher ratings on teacher performance. Draft. Retrieved from http://home.uchicago.edu/ npope/la_ny_paper.pdf,2014.

[20] Ashraf, N., Bandiera, O., \& Lee, S. Awards unbundled: Evidence from a natural field experiment. Journal of Economic Behavior \& Organization. 2014; 100(1): 44-63.

[21] Azmat, G., \& Iriberri, N. The importance of relative performance feedback information: Evidence from a natural experiment using high school students. Journal of Public Economics. 2010; 94(7-8): 435-452.

[22] Murphy, R., \& Weinhardt, F. The importance of rank position. CEP discussion paper no. 1241, Retrieved from http://eric.ed.gov/?id=ED545617,Centre for Economic Performance, 2013.

[23] Cherry, T. L., \& Ellis, L. V. Does rank-order grading improve student performance? International Review of Economics Education. 2005; 4(1): 9-19.

[24] McLean, K. C., \& Syed, M. (2014). The Oxford Handbook of Identity Development, Oxford University Press New York, 2014.

[25] Kemph, J. P. Identity, youth and crisis. Journal of Behavioral Science. 1969; 14(2): 154-159.

[26] Sokol, J. T. Identity development throughout the lifetime: An examination of Eriksonian theory. Graduate Journal of Counseling Psychology. 2009; 1(2): 1-14.

[27] Creswell, J. W. (2009). Research design: Qualitative, quantitative, and mixed methods approaches (3rd ed), Sage Publications, Thousand Oaks, Calif, 2009.

[28] Creswell, J. W., \& Clark, V. L. P. Designing and conducting mixed methods research. Sage Publications, Thousand Oaks, Calif, 2011.

[29] Cronbach, L. J. Coefficient alpha and the internal structure of tests. Psychometrika. 1951; 16(3): 297-334.

[30] Panayides, P. Coefficient alpha: Interpret with caution. Europe's Journal of Psychology. 2013; 9(4): 687-696.

[31] Schmitt, N. Uses and abuses of coefficient alpha. Psychological Assessment. 1996; 8(4): 350-353.

[32] Bailey, J. A. The foundation of self-esteem. Journal of the National Medical Association. 2003; 95(5): 388.

[33] Govindarajan, K. A study on self-esteem and achievement in Mathematics of secondary school students. International Journal of Current Research. 2013; 5(9): 2563-2565.

[34] Leder, G. C. Teacher student interaction: A case study. Educational Studies in Mathematics. 1987; 18: 255-271. 
[35] Murray, C., \& Zvoch, K. Teacher-Student relationships among behaviorally at-risk African American youth from lowincome backgrounds: Student perceptions, teacher perceptions, and socio-emotional adjustment correlates. Journal of Emotional and Behavioral Disorders. 2011; 19(1): 41-54.

[36] Jadama, L. M. Impact of subject matter knowledge of a teacher in teaching and learning process. Middle Eastern \& African Journal of Educational Research. 2014; 7(1): 20-28.

[37] Kazi, A. S., \& Akhlaq, A. Factors affecting students' career choice. Journal of Research \& Reflections in Education (JRRE). 2017; 11(2): 187-196.
[38] Bradley, S., Crouchley, R., Millington, J., \& Taylor, J. Testing for quasi-market forces in secondary education. Oxford Bulletin of Economics and Statistics. 2000; 62(3): 357-390.

[39] Lassibille, G., Pengtan, J. \& Sumra, S. Impact of evaluation of education Reforms. Working Paper No 12 On: Expansion of Private Secondary Education: Experience and Prospects in Tanzania, Development Research Group- The World Bank, Dar es Salaam, 1998.

[40] Ofsted. Office of standard in education. Guidance on Inspection of Secondary Schools. HMSO, London, 1999. 